\title{
The decline in volatility in the US economy. A historical perspective *
}

\author{
María Dolores Gadea ${ }^{\dagger} \quad$ Ana Gómez-Loscos ${ }^{\ddagger}$ \\ University of Zaragoza Banco de España \\ Gabriel Pérez-Quirós § \\ Banco de España and CEPR
}

November 23, 2018

\begin{abstract}
In this paper, we analyze the volatility of US GDP growth using quarterly series starting in 1875 . We find structural breaks in volatility at the end of World War II and at the beginning of the Great Moderation period. We show that the Great Moderation volatility reduction is only linked to changes in expansions, whereas that after World War II is due to changes in both expansions and recessions. We also propose several methodologies to date the US business cycle in this long period. We find that taking volatility into account improves the characterization of the business cycle.
\end{abstract}

JEL classification: C22, E32

Keywords: business cycle, volatility, structural breaks, secular changes

\footnotetext{
${ }^{*}$ We are very grateful to J. Gali, P. Perron, J. Stock and participants at Banco de España seminar, World Congress of the Econometric Society 2015, European Economic Association Conference 2015 and "Largescale Crises: 1929 vs 2008" Conference 2015, the editor and three anonymous referees for their comments and suggestions. Maria Dolores Gadea acknowledges the financial support from Spanish Ministerio de Ciencia, Innovación y Universidades (MICINU), Agencia Española de Investigación (AEI) and European Regional Development Fund (ERDF, EU) under grants ECO2017-83255-C3-1-P and ECO2017-83255-C3-3-P.

${ }^{\dagger}$ Department of Applied Economics, University of Zaragoza. Gran Vía, 4, 50005 Zaragoza (Spain). Tel: +34 9767 61842, fax: +34 976761840 and e-mail: lgadea@unizar.es

${ }^{\ddagger}$ Banco de España, Alcalá, 48, 28014 Madrid (Spain). Tel: +34 91 3385817, fax: +34 915310059 and e-mail: agomezloscos@bde.es

$\S$ Banco de España, Alcalá, 48, 28014 Madrid (Spain). Tel: +34 91 3385333, fax: +34 915310059 and e-mail: gabriel.perez@bde.es
} 


\section{Introduction}

The significant decline in macroeconomic volatility that began in the mid-1980s in the US economy, known as the Great Moderation (GM, henceforth), is one of the most important stylized facts of the modern macroeconomy. A great deal of empirical work has appeared since the seminal papers of Kim and Nelson (1999) and McConnell and Perez-Quiros (2000). To quote some recent ones, Stock and Watson (2017) consider that the Great Moderation lasted through the beginning of the global financial crisis, while Gadea-Rivas et al. (2018) show that the Great Recession (GR, henceforth) does not represent the end of the GM. Most of the papers that analyze the GM use post-World War II (WWII, henceforth) data I

Within this framework, this paper presents a threefold contribution. First, we analyze whether the volatility decline of the Great Moderation holds in a long-run perspective. We use quarterly data, which is a novelty in this strand of literature, since 1875, also considering data after the Great Recession. We find that the GM still holds when we include a very long time series in which the US economy underwent substantial transformations. Standard structural break tests document changes in the volatility of the US GDP growth rate around 1946 and 1984 2 Second, we identify that the first volatility break is due to changes in the features of both business cycle phases (expansions and recessions), while the GM break is only linked to changes in the features of expansions. Third, we date the US business cycle for a very long time period, proposing several methodologies to capture the role of volatility changes. We show that the characterization of the business cycle can be improved by explicitly allowing for regime shifts and volatilty breaks.

The structure of the paper, after this Introduction, is as follows. In Section 2, we analyze the US GDP growth rate since the late 19th century and test for the presence of structural breaks both in its mean and variance. We use quarterly data

\footnotetext{
${ }^{1}$ For a discussion on data concerns over a sample since the end of the 19th century, see Romer (1986a b, 1991, 1999). She states that the prewar economy, due to different construction of the data, was even more volatile than the postwar one, which would make it more difficult to find a structural break associated with the GM. However, in site of this issue, there are some valuable exceptions in a series of papers by Keating and Valcarcel (2012, 2015, 2017) and Nason and Smith (2008). There are also some papers that analyze the standard deviation of output in the pre-GM period. See Basu and Taylor (1999) and DeLong and Summers (1986).

${ }^{2}$ This finding is consistent with the work of Keating and Valcarcel (2012, 2015, 2017) and Nason and Smith (2008), which reach the same conclusions using annual data and various complementary methodologies to the ones we use in this paper. For instance, Keating and Valcarcel (2017) use a time-varying VAR as well as other techniques, such as a Markov Switching ARCH model.
} 
from the NBER. We do not find breaks in the mean, but we obtain different volatility breaks that show a secular reduction in the variability of output (Section 3). We identify two structural breaks approximately located at the end of World War II and at the beginning of the GM. The WWII decline in volatility could be related to changes over time in economic structure such as the diminished importance of agriculture in favor of industry and services, the increase in financial organization and the implementation of countercyclical policies, among others ${ }^{3}$ The GM decline in volatility is usually related to three different factors: changes in the structure of production, improved policy and good luck ${ }^{4}$ In Section 4, we identify the main features that characterize the three volatility periods that we find. A thorough study suggests that they respond to different features of the cyclical phases. Specifically, the post-WWII volatility reduction is associated with changes in both expansions and recessions, while that of the GM is associated with changes in the early stages of expansions. In Section 5, we illustrate the risks of turning a blind eye to volatility when analyzing the business cycle of the US economy in the long run. To that end, we use a standard Markov Switching (MS) framework and find that this model does not identify a recession after WWII, unless we take volatility changes into account. Thus, we propose, two novel ways of modeling US economic growth: a MS model with endogenous structural breaks in volatility and a MS model with up to three variance regimes. We find that models that control for volatility perform better than those that do not. Additionally, we check the robustness of our results with a Finite Mixture Markov Switching method, which allows some flexibility in the choice of business cycle states. We find that taking volatility into account in this model improves the accuracy of the characterization of the US business cycle.

Overall, this paper suggests that there is a structural volatility decline from a long-term perspective and valuable information is missed if we ignore heteroskedasticity. We find that the WWII volatility reduction is different from the Great Moderation one with respect to the relative role played by the business cycle phases. We also show that it is necessary to consider volatility breaks in order to date the US business cycle correctly. Indeed, changes in the signal-to-noise ratio associated with the changes in the volatility of the series make standard procedures of business cycle dating seriously misleading.

\footnotetext{
${ }^{3}$ See, for instance, Burns (1960), Basu and Taylor (1999) and DeLong and Summers (1986).

${ }^{4}$ See, for instance, Stock and Watson (2002), Ahmed et al. (2004), and Gali and Gambetti (2009).
} 


\section{Analysis of the series}

The seminal papers of Kim and Nelson (1999) and McConnell and Perez-Quiros (2000) and, as far as we know, the academic work that analyzes the phenomenon of volatility reduction, have focused on the postwar period up to before the Great Recession 5 However, we believe that properly understanding the magnitude and the main features of the GM requires considering a broad historical context. To that end, we employ quarterly real US GDP data from the NBER ${ }^{6}$ covering the sample period 1875.1-2014.2. This approach, that considers historical data from the nineteenth century as well as more recent data, will let us to know the importance of the GM in relation to other major historical macroeconomic events and enable us to construct a precise long-term business cycle chronology using different methodologies. The GDP growth rate, calculated as the first logarithmic difference, is displayed in Figure 1. A simple look at GDP data reveals that the intensity of the shocks and the shape of business cycles have changed over 140 years of macroeconomic history. The sample begins just after the panic of 1873 , when the US economy was still facing its consequences. A few years later, the US economy had to cope with the aftermath of the 1893 panic. In the twentieth century, the US economy suffered the effects of WWI (1914-1918). However, some of the most influential economic events of the past century were the Crash of 1929, with devastating economic effects during the next decade, and WWII (1939-1945). Then, there was a post-war economic boom until the 70s with the end of the Bretton Woods system and substantial oil price shocks, economic growth became stagnant and inflation grew. In the 80s, a reversal of these disequilibria was achieved and the US economy experienced a reduction in the volatility of the business cycle. During this period, called the GM, the US enjoyed long economic expansions only interrupted by three recessions. The first two, 1990-91 and 2001, were mild by historical standards. However, following the burst of the housing bubble, the US economy entered into a severe recession (2007-2009) that has been followed by a weak recovery.

Although we focus on breaks in the variance, we first examine the possibility of changes in the mean, as their existence could affect the identification of the former.

\footnotetext{
${ }^{5}$ Only Gadea-Rivas et al. (2018) introduce the period of the GR into the sample, concluding that it was not able to break the stability of the GM and would not do so, even if the GR and its recovery had lasted for a significant period of time (15 years or even more).

${ }^{6}$ The historical series has been obtained from http://www.nber.org/data/abc/
} 


\subsection{Stability of GDP growth in the long run}

We analyze the stability in the mean of the GDP growth by applying a methodology that tests for the existence of an unknown number of structural breaks in the mean of GDP growth. We apply the approach of Bai and Perron (1998, 2003a b) (BP), which is based on the principle of global minimizers of the sum of squared residuals. To our knowledge, we are the first to formally test for changes in the mean in such a long sample.

The BP methodology consistently determines the number of break points over all possible partitions as well as their location. We consider two models, Model 1, a model with just one constant representing a mean growth rate, and Model 2, which adds an standard autoregressive model of order 1.7]

Bai and Perron (1998) suggest three types of tests to select the number and location of breaks, which are detailed in Table 1. A maximum number of 5 breaks has been considered, which, along with the sample size, $T=549$, supposes a trimming of $\epsilon=0.15$. The process is allowed to present autocorrelation and heteroskedasticity. A non-parametric correction has been employed to consider these effects. As can be seen in Table 1, there is no structural break in the mean; all the statistics are way below the critical value. So, we can safely assume that possible breaks in variance can not be driven by the misspecification of the mean parameters.

Although we do not find statistical evidence of a structural break in the mean of US GDP growth rate, we acknowledge there could be more subtle forms of instability in the mean given the evolution of the series. As a robustness check, to consider these potential instabilities, we follow the approach of Gadea-Rivas et al. (2018) and we model the average growth as a time-varying parameter, as in Stock and Watson (1998). We find that the mean exhibits a very small but non-negligible variation over the sample. In any case, we take this trend into account when analyzing volatility.

\section{$2.2 \quad$ Volatility developments}

We propose several methods to test for the significance of changes in the variance in the US GDP growth rate series. First, we use Inclán and Tiao (1994)'s (IT) test to detect changes in the unconditional variance of the series, which has been used extensively, especially in financial series. This test uses an Iterated Cumulative Sum of Squares (ICSS) and assumes that the innovations are zero-mean normally,

\footnotetext{
${ }^{7}$ We verify, through a battery of unit root tests, that the series is stationary.
} 
i.i.d. random variables. However, the IT test has big size distortions when the assumption of normally distributed innovations fails in the fourth order moment or for heteroskedastic conditional variance processes and, consequently, it tends to overestimate the number of breaks. Given that the variance is not constant over time and the distribution of GDP growth is non-mesokurtic with a fat right tail, we apply the corrections proposed by Sanso et al. (2004) for high kurtosis and heteroskedastic conditional variance processes. We denote this corrected $I T$ tests as $\operatorname{IT}\left(\kappa_{2}\right)$. Table 2 shows the results of applying this test to US GDP growth and conclude that there are three breaks in the variance, chronologically located in 1917.4, 1946.2 and 1984.1, that roughly correspond to the end of each of the world wars and the beginning of the GM. Notice that neither the Great Depression nor the Great Recession mean a structural break in the GDP data generating process.

These results are confirmed with an analysis within the parametric framework which consists of applying the BP test to the mean of the absolute value of the estimated residuals 8 We obtain the same break points that with the IT test, 1947.1, 1984.2 and 1917.3 in this order. Indeed, the last break is not always detected.

We also compute the method used in McConnell and Perez-Quiros (2000). This is a parametric test of the changes in volatility when the mean and variance parameters are estimated jointly. We apply the test in a sequential procedure, only finding two breaks: that associated with the GM (1984.3) and another one close to the end of WWII (1951.1). The break in 1917 is not even found. Finally, we find the same results if filtering the series by removing the trend and applying the different structural break tests 9

The forces that could have determined the two changes in volatility are of different natures. The WWII volatility decline could be related to major historical changes in the structure of the US economy. Indeed, Burns (1960), Basu and Taylor (1999) and DeLong and Summers (1986) mention a set of major changes in the US that modified the business cycle. For instance, they highlight the loss of relevance of agriculture in favor of industry and services, the increase in financial organization

$\varepsilon$ Zhou and Perron (2008) show that, if there are structural breaks that are not taken into account in the mean of the series, the test suffers from serious size distortions. However, our series do not have any changes in the mean as we have found previously. This method has been used by Herrera and Pesavento (2005), Stock and Watson (2002), and Gadea-Rivas et al. (2018) among others.

${ }^{9}$ Our results are in line with the literature. Keating and Valcarcel (2012, 2015, 2017) and Nason and Smith (2008) find a postwar volatility moderation and another one related to the Great Moderation. The postwar volatility reduction was more substantial than that of the Great Moderation. 
and the implementation of countercyclical policies, among others 10

The explanations of the GM volatility decline fall into three categories. First, the decrease of US GDP fluctuations could be due to changes in the structure of production; in particular, the improvement in inventory investment and in supply chain management, the tertiarization of the economy and increased competition in products markets. The second explanation emphasizes the improvement of economic policy as a result of the implementation of monetary stabilization policies with inflation targets and of the creation of independent monetary authorities. Third, good luck, that is, the absence of significant exogenous shocks might also have played an important role in tempering economic fluctuations. However, there is no consensus on the relative importance of these causes. See Stock and Watson (2002), Ahmed et al. (2004), Giannone et al. (2008), Canova (2009), Gali and Gambetti (2009) and Canova and Gambetti (2010).

\section{$3 \quad$ Fathoming volatility changes}

Results in previous section robustly confirm the existence of different periods in the US business cycle. In this section, we intend to shed some light on the characteristics of these different volatility periods.

Given that the break in 1917 is less robust and to make the discussion clearer, we divide the sample into three subsamples. Period 1, covering up to the end of WWII; period 2, from the end of WWII to the beginning of the GM and; period 3, from the beginning of the GM to the end of the sample In Table 3, we show some descriptive statistics that provide some interesting facts about the nature of the secular volatility reduction. All the three subsamples present similar means while the reduction in volatility is clearer between subsamples 1 and 2 than between 2 and 3. However, the difference between periods 2 and 3 (the second break) is clearly associated with a change in volatility and it seems that changes in higher moments of the distribution could also play a role. Indeed, skewness and kurtosis change 12

\footnotetext{
${ }^{10}$ In addition, Romer (1986a b, 1991) considers that this could also be due to data construction.

${ }^{11}$ To offer some evidence on the idiosyncrasy of each of the three periods, Gadea-Rivas et al. (2015) compute the Kolmogorov-Smirnoff test for equal distribution across subsamples. We clearly reject the null hypothesis that the post-WWII subsample is statistically equal to the pre-WWII sample, and also reject that the GM subsample is statistically equal to both.

${ }^{12}$ We run a bootstrap exercise and find that there are no significant differences in kurtosis between periods 1 and 2, while 3 is different from both. Regarding skewness, the results are less clear: the three periods are significantly different, but periods 1 and 2 are more similar.
} 
To see whether these changes are associated with changes in the shape of the business cycle, we describe business cycle characteristics using the NBER dating that pinpoints the turning points. Following Harding and Pagan (2002), we dissect the business cycle and calculate some outcomes for each phase, trough-to-peak for expansions and peak-to-trough for recessions. We obtain the mean duration (in quarters), amplitude (this compares the log level of GDP at the turning points), cumulation (this is the cumulated gain or loss and consists of the sum of the amplitudes of each cyclical phase) and excess (this refers to the difference between the real area drawn by the path of the GDP growth and the hypothetical triangle which would have formed with a uniform growth rate throughout the whole phase) ${ }^{13}$ of recessions and expansions, 14

As we mentioned earlier, the changes from the first to the second subsample are of a different nature than those from the second to the third subsample. From pre-WWII to post WWII, the changes in the characteristics can be directly linked to changes in the features corresponding to recession phases (Table 4). For example, there are shorter and shallower recessions while the expansions are similar in both subsamples. On the contrary, the difference between periods 2 and 3 are basically due to changes in the shape of expansion phases whose duration is strikingly higher and whose excess has fallen dramatically in the last period. Changes in recession periods such as those in the pre-WWII to post-WWII period reduce volatility to a pure accounting exercise. Recessions are, in general, more volatile than expansions. Therefore, less frequent and shorter recession periods reduce volatility. On the contrary, the second reduction in volatility, that associated with the GM, is more subtle. Recession features before and after the GM are basically equal. The biggest change in the characteristics associated with the GM is in the shape of expansion periods, that is, in the excess.

To develop this idea in greater depth, we consider different scenarios on the characteristics of each of the business cycle phases. First, we select recessions (expansion) according to the NBER chronology. Second, we replace the recessions (expansions) of each period with others taken randomly from a different period,

\footnotetext{
${ }^{13}$ In the case of expansions, a positive Excess (concave path) means that the recovery starts with a high growth rate and goes on slowly, whereas a negative Excess (convex path) is produced when the economy has a smooth beginning that becomes sharper at the end.

${ }^{14}$ The measures can be defined as follows. Duration: $\overline{0 T} ;$ Amplitude: $\overline{0 P} ;$ Cumulation: $\int_{0}^{T} f(t) d t$; and Excess: $\int_{0}^{T} f(t) d t-(\overline{0 T} * \overline{0 P}) / 2$. See Gadea et al. (2017) for a graphical illustration.
} 
while keeping the expansions (recessions) unchanged. Specifically, we remove each recession (expansion) of period " $\mathrm{x}$ " and replace it with a recession (expansion) of period "y", chosen randomly ${ }^{15}$ We repeat this experiment for 10,000 iterations, estimate the number and location of volatility structural breaks and compute the percentage of times that the structural breaks associated with WWII and the GM are found.

The idea of the exercise is the following. If, for a given period " $\mathrm{x}$ " (e.g. from WWII to the GM), we substitute its recessions (or expansions) by those of the other period "y" (e.g. GM) and we do not find a structural break from " $\mathrm{x}$ " to "y" anymore, we could conclude that these recessions (expansions) explain the changes in volatility and, when looking for an explanation, we should concentrate on understanding the characteristics in those recession (expansion) periods.

Concerning the empirical results, first, we change the recessions of period 2 for the recessions of 1, finding that the structural break of WWII holds only in $48 \%$ of the cases. This result could mean that the nature of the WWII volatility break in more than half of the cases is associated with the characteristics of recession phases. Second, if we change the recessions of period 3 for the recessions of 2 , we obtain the GM structural break in $100 \%$ of the cases. Thus, in no case, were recessions characteristics behind the GM break in volatility because despite using recessions (duration, amplitude and excess) of the previous period, the break is still identified.

So, is it characteristics of expansion periods that explain the lower volatility from one period to the next? To find out, first, we change the expansions of period 2 for those of period 1 and find that the structural break of WWII is identified in $31 \%$ of the cases. Adding these results to the previous ones about recessions, we conclude that it is a mixture of the features of the expansions and recessions that explains the post-WWII volatility reduction. However, if we change the expansions of period 3 for those of 2 , in no case does the structural break of the GM hold. Again, combining these results with the previous ones about recessions, we can conclude that the nature of the GM structural break is entirely explained by the features of expansion phases. To examine power and size of our findings, we have performed some Monte Carlo exercises which confirm their good properties. See Online Appendix A.

These findings reinforce those obtained by Gadea-Rivas et al. (2018) who, using

\footnotetext{
${ }^{15}$ In particular, we replace each recession from peak to through (or expansion from through to peak) independently of their duration.
} 
a different empirical strategy, show that the decrease in output growth volatility of the GM seems to be clearly associated with the shape of expansions and, specifically, with the disappearance of high-growth recoveries. Broadening our perspective with a longer dataset, the results suggest that the secular fall in volatility responds to two structural changes of a different nature. The post-WWII volatility reduction is related to changes in both cyclical phases, while that of the GM is primarily due to the characteristics of expansions.

\section{Chronology of the US business cycle. The risks of turning a blind eye to volatility}

After having identified the presence of structural volatility breaks in the series and their different natures, we show the risks of not taking them into account when modeling the business cycle. In this section, we analyze the hidden business cycle of the US GDP growth in the long run. We aim to show the difficulties of properly dating the business cycle if we do not take volatility into account 10

The most popular method that allows us both to date the cycle and to make inferences about future periods is the Markov Switching approach developed by Hamilton (1989) ${ }^{17}$ This approach characterizes the evolution of a variable through a process of conditioned mean to a state of a specific nature. The changes in value in this dynamic process will allow us to distinguish between periods of expansion and contraction. Regime shifts are governed by a stochastic and unobservable variable which follows a Markov chain. In general, we consider the following process for the growth of GDP, calculated as first log difference:

$$
y_{t}=\mu_{S_{j}}+\epsilon_{t}
$$

where $y_{t}$ is US GDP growth rate, $\mu_{S_{j}}$ is the vector of MS intercepts and $\epsilon_{t}-S_{j}$ $\sim \mathrm{N}(0, \sigma)$. It is standard to assume that these varying parameters depend on

\footnotetext{
${ }^{16}$ The purpose of the related literature that analyzes volatility in the long run is to account for changes in volatility of output growth and inflation using a broad set of tools. For instance, Nason and Smith (2008) select structural breaks in volatility exogenously and use the unconditional consumption-capital-asset-pricing model. Keating and Valcarcel (2012, 2015) employ a time-varying parameter VAR for real output and inflation, while Keating and Valcarcel (2017) applies a wide set of econometric models to give robustness to the results obtained by using a time-varying parameter VAR. Those are state-space stochastic volatility models, Markov Switching ARCH and GARCH.

${ }^{17}$ For a comparison of different business cycle dating methods, see Layton and Katsuura (2001) and Chauvet and Piger (2008).
} 
an unobservable state variable $S_{j}$ that evolves according to an irreducible $m$-state Markov process where $p_{i j}$ controls the probability of a switch from state $j$ to state $i$.

In this framework, we estimate a MS model with 2 states $(j=1,2)$ and a constant variance for the full period:

$$
\begin{aligned}
& y_{t}=\mu_{1}+\epsilon_{t} \text { for state } 1 \\
& y_{t}=\mu_{2}+\epsilon_{t} \text { for state } 2
\end{aligned}
$$

Assuming a classical cycle, $\mu_{1}$ and $\mu_{2}$ are associated with expansion and recession phases, respectively, and $p_{11}=p$ and $p_{22}=q$ represent the probability of being in expansion/recession and staying in the same state. The estimated parameters are displayed at the top of Table 5 and Figure 2 presents the model-estimated probability of being in recession, which is compared with the NBER official chronology. We find the surprising result that the MS model identifies no recession after WWII. It is clear that ignoring the existence of volatility changes in the series leads to model misspecifications 18 To capture this phenomenon, we adopt a dual strategy in the MS estimation: introducing structural changes in the variance and considering different variance regimes.

\subsection{A MS model with structural breaks in variance}

We extend the previous approach to consider the presence of a maximum of $M$ structural breaks in (2) which defines $M+1$ regimes with different means and variances but maintaining the same transition matrix across periods 19 Although, on the basis of previous results, we are particularly interested in changes in variance,

\footnotetext{
${ }^{18}$ McConnell and Perez-Quiros (2000) show the difficulties of this method in describing turning points in the presence of structural breaks in volatility. If these breaks exist, $\mu_{1}$ and $\mu_{2}$ should change proportionally to capture business cycle characteristics.

${ }^{19}$ Relaxing the assumption that the transition matrix is the same across periods would be the same as a piecewise estimation which would go against the objective of this exercise (that is, to find structural breaks in a common MS process). Note that the parameters of the transition matrix are the only ones that maintain the nexus of the process. In addition, piecewise estimates would have higher standard errors as a result of the smaller sample size.
} 
we also allow the mean of both states to differ in each regime,

$$
\begin{aligned}
& \mu_{1}^{1}, \mu_{2}^{1}, \sigma_{1} \text { for regime } 1 \\
& \ldots \\
& \mu_{1}^{M+1}, \mu_{2}^{M+1}, \sigma_{M+1} \text { for regime } M+1
\end{aligned}
$$

We propose this innovative strategy as a methodological alternative to include changes in variance in MS frameworks. We take a maximum number of 3 breaks and estimate all possible break points in volatility (with a minimum interval of 5 years) ${ }^{20}$ selecting their location in accordance with the SBIC. Table 5 shows the results of the estimation for the cases of 1, 2 or 3 structural breaks and Figure 2 displays the different probabilities. We find that considering structural changes greatly improves the precision with which the turning points are located, as evidenced by the value of the SBIC, which selects a model with 2 breaks and 3 regimes $\left(-2.13 \times 10^{3}\right)$. The two breaks are located in 1946.2 and 1984.2, almost exactly the same points detected by the test of changes in volatility ${ }^{21}$ The period up to the first break is characterized by a very high variance and heavy falls during recessions. The period between the end of WWII and the onset of the GM shows a significant reduction in volatility with sustained expansions and less pronounced downturns. Finally, the GM period has a low variance and moderate growth rates.

\subsection{A MS model with variance regimes}

McConnell and Perez-Quiros (2000) propose to modify the MS model to include two regimes of variance over the period 1953-1999. In this subsection, we augment the MS model specification of these authors by including up to three states for the variance which are driven by a Markov chain that is independent of the one that drives the states of the mean. The advantage of this specification, compared to considering volatility breaks, is that the same variance regime can be identified in different periods, capturing volatility more accurately. In addition, as we do for the mean, we date the states of the variance endogenously and can make inferences about future states of volatility because we have an estimate of the transition matrices for

\footnotetext{
${ }^{20}$ We take as a reference the results obtained in the previous sections to decide the maximum number of regimes.

${ }^{21}$ The gain with respect to the model with 3 breaks (the other one located in 1917.3) is very small $\left(-2.09 \times 10^{3}\right.$ in the case of two breaks against $-2.09 \times 10^{3}$ in the case of three breaks). See Gadea-Rivas et al. (2015)
} 
the volatility states as well.

We consider two specifications for our analysis. The first is that of McConnell and Perez-Quiros (2000). It yields two possible states for the variance, $\sigma_{1}$ being the variance in the high-variance state and $\sigma_{2}$ the variance in the low-variance state, along with four possible states for the mean of output growth corresponding to different variances and cyclical phases.

$$
\begin{aligned}
& \mu_{1}^{1}, \sigma_{1} \text { for expansion and high variance regime } \\
& \mu_{2}^{1}, \sigma_{1} \text { for recession and high-variance regime } \\
& \mu_{1}^{2}, \sigma_{2} \text { for expansion and low-variance regime } \\
& \mu_{2}^{2}, \sigma_{2} \text { for recession and low-variance regime }
\end{aligned}
$$

However, our dataset is longer and has more frequent and dramatic volatility changes than that of McConnell and Perez-Quiros (2000). So, in the second specification, we extend, for the first time, their proposal by allowing three possible regimes for the Markov chain that governs the variance, $\sigma_{1}$ for the high-variance regime, $\sigma_{2}$ for the medium-variance regime and $\sigma_{3}$ for the low-variance regime. Consequently, the number of states increases to six, depending on the two values of $S_{t}$ and the three variance regimes.

$\mu_{1}^{1}, \sigma_{1}$ for expansion and high-variance regime

$\mu_{2}^{1}, \sigma_{1}$ for recession and high-variance regime

$\mu_{1}^{2}, \sigma_{2}$ for expansion and medium-variance regime

$\mu_{2}^{2}, \sigma_{2}$ for recession and medium-variance regime

$\mu_{1}^{3}, \sigma_{3}$ for expansion and low-variance regime

$\mu_{2}^{3}, \sigma_{3}$ for recession and low-variance regime

The estimated parameters appear in Table 6. Both models improve their performance with respect to the MS with structural breaks. Furthermore, the model with three variance regimes has the highest SBIC $\left(-1.96 \times 10^{3}\right)$. The results with three regimes are shown in Figure 3. Regime 1 (high-variance) lasts until 1951.1, although some periods of medium variance also appear interspersed. Regime 2 (medium-variance) is detected in the interval 1950.2-1984.2 as well as during the recent GR ${ }^{22}$ Moreover, it is also found occasionally in the pre-WWII period, precisely

\footnotetext{
${ }^{22}$ The change to the medium-variance regime occurs between 2008.3 and 2009.2 and then there is a return to the low-variance regime (in line with the volatility increase of the rolling estimation).
} 
when a high-variance regime is not detected. Regime 3 (low-variance) corresponds to what we know as the GM.

Overall, we have illustrated how to date the US business cycle, taking differences in volatility into account, extending the traditional MS approach. A MS model with two structural breaks in variance performs better than a traditional MS, which does not identify any recession after WWII. We are even able to compute a model with three endogenous variance regimes which slightly improves the results of the MS model with structural breaks. Hence, considering volatility in different Markov Switching specifications improves the US business cycle dating, that is, the model-estimated probability of being in recession of different Markov Switching specifications with respect to the NBER official chronology is more precise.

\subsection{Finite Markov Mixture Models}

In this subsection, with a view to assessing the robustness of our results, we consider an alternative strategy - applied, for the first time, to model US GDP in the long run - that allows us flexibility in the characterization of the states and to endogenously determine their number. It combines both the possibility of different volatility and mean regimes and a business cycle dating without imposing restrictions on the number of these clusters/states.

In particular, the business cycle design is not pre-defined and the clusters of normal distributions are estimated according to different mean growth and variance parameters and an additional switching parameter, without specifying a priori the number of possible states derived from these parameters. On the contrary, in the MS approach, the number of states of the mean (expansion and recession) and the number of variance regimes are a priori defined.

The Finite Markov Mixture Models (FMMM) (see Frühwirth-Schnatter (2006) for a detailed revision) combine clustering techniques, finite mixtures and Bayesian approaches, which leads to a rich class of non-linear models. ${ }^{23}$ Hence, they are a good choice when the unobservable latent indicator that drives the process is a Markov chain. FMMM are often used for the purpose of clustering. This approach assumes the existence of $K$ hidden groups and intends to reconstruct them by fitting a $K$ component mixture density. The groups may be labeled through a discrete indicator variable $S_{t}$ taking values from 1 to $K$. The time series $\left\{y_{1}, \ldots, y_{T}\right\}$ is assumed to be

\footnotetext{
${ }^{23}$ Some applications of these techniques to the analysis of the business cycle can be found in Fruhwirth-Schnatter and Kaufmann (2008) and Hamilton and Owyang (2012).
} 
a realization of a stochastic process $Y_{t}$ generated by a finite Markov mixture from a specific distribution family. For each $t$, the distribution of $Y_{t}$ arises from one of $K$ distributions $\Upsilon\left(\theta_{1}\right), \ldots, \Upsilon\left(\theta_{K}\right)$, that depends on the state of $S_{t}$. $\theta_{k}$ collects the parameters of the distribution when $S_{t}=k$,

$$
Y_{t} \mid S_{t}=k \sim \Upsilon\left(\theta_{k}\right)
$$

The stochastic properties of $S_{t}$ are described by the $K \times K$ transition matrix $\xi$ where

$$
\xi_{j k}=P\left(S_{t}=k \mid S_{t-1}=j\right), \forall j, k \in\{1, \ldots, K\}
$$

that corresponds with a irreducible Markov chain which ergodic probabilities $\eta_{k}=$ $p\left(S_{k} \mid \xi\right)$, that represent the relative size of each group.

For the stochastic process $\left\{S_{t}, Y_{t}\right\}_{t=1}^{T}$, the marginal distribution of $Y_{t}$ is

$$
p\left(y_{t} \mid \varphi\right)=\sum_{k=1}^{K} p\left(y_{t} \mid S_{t}=k, \varphi\right) p\left(S_{t}=k \mid \varphi\right)
$$

with $\varphi=\left(\theta_{1}, \ldots, \theta_{k}, \eta\right)$.

In our case, where the GDP growth, $y_{t}$, is an observed discrete signal with noise, we can define the Markov mixture of normal distributions as follows,

$$
y_{t}=\left\{\begin{aligned}
\mu_{1}+\varepsilon_{t}, & \varepsilon_{t} \sim N\left(0, \sigma_{1}^{2}\right), S_{t}=1 \\
& \ldots \\
\mu_{k}+\varepsilon_{t}, & \varepsilon_{t} \sim N\left(0, \sigma_{k}^{2}\right), S_{t}=K
\end{aligned}\right.
$$

So, we estimate $K$, the number of states of the hidden Markov chain, the state-specific parameter and the ergodic probabilities from the transition matrix: $\varphi=\left(\theta_{1}, \ldots, \theta_{k}, \eta\right)$. We use a Bayesian approach with Markov Chain Monte Carlo (MCMC) methods and Gibbs Sampling to estimate the posterior probability $p(\varphi \mid S, y)$; 5,000 draws and non-informative priors are considered ${ }^{24}$ Given the previous results, we start by considering a maximum number of four components $(\operatorname{Kmax}=4)$. Then, we consider the simple representation of the draws generated by the MCMC algorithm for $\mu$ and $\sigma$. Furthermore, we consider AIC, SBIC, Bayes factor and entropy to obtain the best cluster classification 25 Details of the results for each sub-period

\footnotetext{
${ }^{24}$ All the calculations of this section have been done using the Matlab Toolbox provided by Fruhwirth-Schnatter and Kaufmann (2008).

"These results are available upon request.
} 
appear in Table 7 and Figures 4-6. Each figure includes three panels. Panel (a) displays the scatterplot of MCMC draws for $\mu$ and $\sigma$, with the spread of the clouds representing the uncertainty of estimating the points. Panel (b) represents the probability of being in each state. Finally, panel (c) shows the classification of the GDP growth rates over time based on belonging to each state.

Firstly, we apply FMMM to the whole sample (Figure 4 and first panel of Table 7) finding that the most suitable number of clusters/states is four. The first is characterized by high growth and high variance, the second by negative growth and high variance, and the other two states present moderate growth with low variances. The first two states are basically concentrated before WWII. The third state (moderate growth and moderate variance) is located mainly from WWII up to 1984.3, although it appears occasionally before WWII and in 1990.4 and 2008.12009.2 ${ }^{26}$ After this date, we find a fourth period of moderate growth and low variance. Therefore, this model leads to a classification dominated by volatility and sacrifices a plausible business cycle chronology.

If we apply this model to post-WWII in accordance with the date of the volatility break identified in previous sections, we find three states (Figure 5 and second panel of Table 7). The first corresponds to recession and high variance, the second to high growth and high variance and the third to moderate growth and low variance. The first and second are detected mainly before the GM, while the third is located from 1984.3 on. However, the first, which captures well-known crisis episodes, also identifies the 90 s recession and the GR. This classification identifies recession periods as well as two different types of expansions, according to their volatility.

Finally, with data after the GM break, this model identifies three states (Figure 6 and third panel of Table 7). The first two present low variance, the first is characterized by negative or low growth, corresponding to 1990.3-1991.1 and 2008.1-2009.2. It also shows a peak of probability during the deceleration of the 2000's. The second corresponds to moderate growth. The last one has zero probability throughout most of the period considered.

To sum up, volatility matters to distinguish business cycles states. Considering the whole sample, the two phases of the business cycle are not clearly differentiated because both changes in volatility and growth differences are important to select

\footnotetext{
${ }^{26}$ The method clearly finds the GR (which is a transient episode of volatility, similar to the preGM) and, more weakly, the slowdown of the 90s. The NBER identifies another recession period during the last three quarters of 2001 . However, it is not detected by any dating method.
} 
states. When we zoom on the post-WWII period, the chronology is closer to that of the NBER, because there is less dispersion in volatility. When we focus on the calm times of the GM, the states are characterized by changes in growth means because there are no changes in volatility.

Notice that all these results are consistent with our previous findings and also highlight the difficulties of the traditional MS method to accurately date when there are significant changes in volatility. In fact, volatility appears to play an important role in the building of clusters and in the posterior classification of each observation coming from a mixture distribution, sacrificing, in some cases, a more precise chronology. Only in periods with similar variance, such as the post-WWII and, even more, the GM, do we obtain the established cyclical dating.

\section{Conclusions}

Since the late 19th century, the US economy has experienced major economic changes that have affected the characteristics of its business cycle. Over this long time period, we analyze US GDP growth using quarterly data. We find two robust structural breaks in volatility: at the end of World War II and at the beginning of the the Great Moderation, thus distinguishing three different volatility periods.

Furthermore, we identify that the nature of the volatility reduction is very different. The post-WWII reduction is due to changes in both recessions and expansions, while the GM is only linked to the characteristics of expansion periods.

In addition, we propose several methodological approaches that consider different volatility regimes to conduct a long run business cycle dating of the US economy. We show that taking into account changes in volatility, such as the ones linked to WWII or the GM, improves the accuracy of the US business cycle datings. 


\section{References}

Ahmed, S., Levin, A., and Wilson, B. A. (2004). "Recent U.S. Macroeconomic Stability: Good Policies, Good Practices, or Good Luck?" The Review of Economics and Statistics, 86(3), 824-832.

Andrews, D. W. K. (1991). "Heteroskedasticity and autocorrelation consistent covariance matrix estimation." Econometrica, 59(3), 817-58.

Bai, J., and Perron, P. (1998). "Estimating and testing linear models with multiple structural changes." Econometrica, 66(1), 47-78.

Bai, J., and Perron, P. (2003a). "Computation and analysis of multiple structural change models." Journal of Applied Econometrics, 18(1), 1-22.

Bai, J., and Perron, P. (2003b). "Critical values for multiple structural change tests." Econometrics Journal, 6(1), 72-78.

Basu, S., and Taylor, A. M. (1999). "Business Cycles in International Historical Perspective." Journal of Economic Perspectives, 13(2), 45-68.

Burns, A. F. (1960). "Progress towards economic stability." American Economic Review, 50(1), 1-19.

Canova, F. (2009). "What Explains The Great Moderation in the U.S.? A Structural Analysis." Journal of the European Economic Association, 7(4), 697-721.

Canova, F., and Gambetti, L. (2010). "Do Expectations Matter? The Great Moderation Revisited." American Economic Journal: Macroeconomics, 2(3), 183-205.

Chauvet, M., and Piger, J. (2008). "A comparison of the real-time performance of business cycle dating methods." Journal of Business 83 Economic Statistics, 26, $42-49$.

DeLong, J. B., and Summers, L. H. (1986). "The Changing Cyclical Variability of Economic Activity in the United States." In The American Business Cycle: Continuity and Change, NBER Chapters, 679-734, National Bureau of Economic Research, Inc.

Frühwirth-Schnatter, S. (2006). Finite Mixture and Markov Switching Models. New York: Springer-Verlag, 1st edn. 
Fruhwirth-Schnatter, S., and Kaufmann, S. (2008). "Model-based clustering of multiple time series." Journal of Business and Economic Statistics, 26, 78-89.

Gadea, M. D., Gomez-Loscos, A., and Perez-Quiros, G. (2017). "Dissecting US recoveries." Economics Letters, 154(C), 59-63.

Gadea-Rivas, M. D., Gómez-Loscos, A., and Pérez-Quirós, G. (2015). "The Great Moderation in historical perspective. Is it that great?" CEPR Discussion Papers 10825, C.E.P.R. Discussion Papers.

Gadea-Rivas, M. D., Gómez-Loscos, A., and Pérez-Quirós, G. (2018). "Great Moderation and Great Recession: From Plain Sailing to Stormy Seas?" International Economic Review, 59(4), 2297-2321.

Gali, J., and Gambetti, L. (2009). "On the Sources of the Great Moderation." American Economic Journal: Macroeconomics, 1(1), 26-57.

Giannone, D., Lenza, M., and Reichlin, L. (2008). "Explaining The Great Moderation: It Is Not The Shocks." Journal of the European Economic Association, $6(2-3), 621-633$.

Hamilton, J. D. (1989). "A new approach to the economic analysis of nonstationary time series and the business cycle." Econometrica, 57(2), 357-84.

Hamilton, J. D., and Owyang, M. T. (2012). "The propagation of regional recessions." The Review of Economics and Statistics, 94(4), 935-947.

Harding, D., and Pagan, A. (2002). "Dissecting the cycle: a methodological investigation." Journal of Monetary Economics, 49(2), 365-381.

Herrera, A. M., and Pesavento, E. (2005). "The Decline in U.S. Output Volatility: Structural Changes and Inventory Investment." Journal of Business and Economic Statistics, 23, 462-472.

Inclán, C., and Tiao, G. C. (1994). "Use of cumulative sums of squares for retrospective detection of changes of variance." Journal of the American Statistical Association, 89(427), 913-923.

Keating, J., and Valcarcel, V. (2012). "Greater moderations." Economics Letters, $115(2), 168-171$. 
Keating, J., and Valcarcel, V. (2015). "The time-varying effects of permanent and transitory shocks to real output." Macroeconomic Dynamics, 19, 477-507.

Keating, J., and Valcarcel, V. (2017). "What's so Great about the Great Moderation?" Journal of Macroeconomics, 51, 115-142.

Kim, C.-J., and Nelson, C. R. (1999). "Has The U.S. Economy Become More Stable? A Bayesian Approach Based On A Markov-Switching Model Of The Business Cycle." The Review of Economics and Statistics, 81(4), 608-616.

Layton, A. P., and Katsuura, M. (2001). "Comparison of regime switching, probit and logit models in dating and forecasting us business cycles." International Journal of Forecasting, 17(3), 403-417.

McConnell, M. M., and Perez-Quiros, G. (2000). "Output Fluctuations in the United States: What Has Changed since the Early 1980's?" American Economic Review, 90(5), 1464-1476.

Nason, J. M., and Smith, G. W. (2008). "Great Moderation(s) and US Interest Rates: Unconditional Evidence." The B.E. Journal of Macroeconomics, 8(1), Article 30.

Romer, C. (1986a). "Spurious volatility in historical unemployment data." Journal of Political Economy, 94(1), 1-37.

Romer, C. D. (1986b). "Is the stabilization of the postwar economy a figment of the data?" American Economic Review, 76 (3), 314-34.

Romer, C. D. (1991). "The cyclical behavior of individual production series, 18891984." The Quarterly Journal of Economics, 106(1), 1-31.

Romer, C. D. (1999). "Changes in Business Cycles: Evidence and Explanations." Journal of Economic Perspectives, 13(2), 23-44.

Sanso, A., Arago, V., and i Silvestre, J. L. C. (2004). "Testing for changes in the unconditional variance of financial time series." Revista de Economia Financiera, 4, $32-53$.

Stock, J. H., and Watson, M. W. (1998). "Median Unbiased Estimation of Coefficient Variance in a Time-Varying Parameter Model." Journal of the American Statistical Association, 93(441), 349-358. 
Stock, J. H., and Watson, M. W. (2002). "Has the business cycle changed and why?" NBER Working Papers 9127, National Bureau of Economic Research, Inc.

Stock, J. H., and Watson, M. W. (2017). "Twenty Years of Time Series Econometrics in Ten Pictures." Journal of Economic Perspectives, 31 (2), 59-86.

Zhou, J., and Perron, P. (2008). "Testing for Breaks in Coefficients and Error Variance: Simulations and Applications." Working Papers Series wp2008-010, Boston University - Department of Economics. 


\section{Tables}

TABLE 1

Multiple structural breaks (BAi-Perron methodology)

\begin{tabular}{ccc|cc}
\hline \hline & Model 1 & Model 2 & \multicolumn{2}{c}{ Critical values } \\
\hline supF_(l+1/l) & & & $5 \%$ & $1 \%$ \\
$\mathrm{l}=0$ & 2.50 & 2.42 & 8.58 & 12.29 \\
$\mathrm{l}=1$ & 2.60 & 1.84 & 10.13 & 13.89 \\
$\mathrm{l}=2$ & 1.35 & 1.29 & 11.14 & 14.80 \\
$\mathrm{l}=3$ & - & - & 11.83 & 15.28 \\
$\mathrm{l}=4$ & - & - & 12.25 & 15.76 \\
UDmax & 2.14 & 1.63 & 8.88 & 12.37 \\
$\mathrm{Nb}(\mathrm{SBIC})$ & 0 & 0 & & \\
$\mathrm{Nb}(\mathrm{LWZ})$ & 0 & 0 & & \\
$\mathrm{Nb}$ Sequential (5\%) & 0 & 0 & & \\
\hline \hline
\end{tabular}

Notes: We look for changes in the mean in a pure structural model (Model 1) and including an autoregressive (Model 2). The trimming parameter is $\epsilon=0.15$ and the maximum number of breaks is 3 . $\mathrm{Nb}$ denotes the number of breaks. Serial correlation and heterogeneity in the errors are allowed. The consistent covariance matrix is constructed using the Andrews (1991) method.

The $\operatorname{supF}_{-}(l+1 / l)$ test takes the existence of $l$ breaks, with $l=0,1, \ldots$, as its $H_{0}$, against the alternative of $l+1$ changes. The $U D \max$ test considers the null of the absence of structural breaks against the existence of an unknown number of breaks. Additionally, SBIC and LWZ criteria are used to select the number of break points. 
TABLE 2

Detecting CHANGES IN VARIANCE

\begin{tabular}{|c|c|c|c|c|}
\hline \multicolumn{5}{|c|}{ Panel A. InClan-TiaO TEST } \\
\hline $\mathrm{IT}\left(\kappa_{2}\right)$ & 1.70 & & \multirow[t]{2}{*}{ Critical value at $5 \%: 1.30$} & \\
\hline $\mathrm{Tb}$ & $1917.4,1946.2,1984.1$ & & & \\
\hline \multicolumn{5}{|c|}{ Panel B. BAI-PERRON METHODOLOGY } \\
\hline & Model 1 & Model 2 & Critical values & \\
\hline & & & $5 \%$ & $1 \%$ \\
\hline \multicolumn{5}{|l|}{$\operatorname{supF}_{-}(1+1 / 1)$} \\
\hline$l=0$ & 75.27 & 58.13 & 8.58 & 12.29 \\
\hline$l=1$ & 32.37 & 24.96 & 10.13 & 13.89 \\
\hline$l=2$ & 32.37 & 24.96 & 11.14 & 14.80 \\
\hline$l=3$ & 0.02 & - & 11.83 & 15.28 \\
\hline$l=4$ & - & - & 12.25 & 15.76 \\
\hline UDmax & 75.27 & 58.13 & 8.88 & 12.37 \\
\hline $\mathrm{Nb}(\mathrm{SBIC})$ & 2 & 2 & & \\
\hline $\mathrm{Nb}(\mathrm{LWZ})$ & 2 & 2 & & \\
\hline $\mathrm{Nb}$ sequential $(5 \%-1 \%)$ & 3 & 3 & & \\
\hline \multirow[t]{3}{*}{$\mathrm{Tb}$} & $1917.3,1947.1,1984.2$ & $1917.2,1946.4,1984.1$ & & \\
\hline & Panel C. MCConnelL & -PEREZ-QUIROS METH & DOLOGY & \\
\hline & Sup & Exp & Ave & $\mathrm{Tb}$ \\
\hline 1875.1-2014.2 & $\begin{array}{l}69.49 \\
(0.000)\end{array}$ & $\begin{array}{l}31.08 \\
(0.000)\end{array}$ & $\begin{array}{l}31.29 \\
(0.000)\end{array}$ & 1984.3 \\
\hline $1875.1-1984.3$ & $\begin{array}{l}31.63 \\
(0.000)\end{array}$ & $\begin{array}{l}12.95 \\
(0.000)\end{array}$ & $\begin{array}{l}10.12 \\
(0.000)\end{array}$ & 1951.1 \\
\hline 1875.1-1951.1 & $\begin{array}{c}6.42 \\
(0.224) \\
\end{array}$ & $\begin{array}{c}1.79 \\
(0.071)\end{array}$ & $\begin{array}{c}2.83 \\
(0.038) \\
\end{array}$ & 1929.4 \\
\hline
\end{tabular}

Notes: See Table 1 for details of the Bai-Perron procedure. IT $\left(\kappa_{2}\right)$ refers to Inclán and Tiao (1994) test with the correction proposed by Sanso et al. (2004) for heteroskedastic conditional variance processes. Nb denotes the number of breaks and $\mathrm{Tb}$ the time of the break.

TABLE 3

DESCRIPTIVE STATISTICS

\begin{tabular}{lccc}
\hline \hline & $1875.2-1946.2$ & $1946.3-1984.2$ & $1984.3-2014.2$ \\
\hline mean & 0.84 & 0.87 & 0.66 \\
median & 1.04 & 0.86 & 0.74 \\
max & 7.97 & 3.91 & 1.87 \\
min & -8.76 & -2.62 & -2.14 \\
st.dev. & 2.92 & 1.18 & 0.60 \\
skewness & -0.50 & -0.16 & -1.32 \\
kurtosis & 3.76 & 3.11 & 6.87 \\
\hline \hline
\end{tabular}

Notes: Computed on the US GDP growth rate. 
TABLE 4

Business CYCLE FEATURES BY PERIODS

\begin{tabular}{lccc}
\hline \hline & $1875.2-1946.2$ & $1946.3-1984.2$ & $1984.3-2014.2$ \\
\hline DURATION & & & \\
\hline Expansions & 9.22 & 13.44 & 27.00 \\
Recessions & 6.61 & 3.75 & 3.67 \\
\hline AMPLITUDE & & & \\
\hline Expansions & 18.59 & 16.16 & 20.76 \\
Recessions & -5.33 & -1.92 & -1.72 \\
\hline CUMULATION & & & \\
\hline Expansions & 142.03 & 179.30 & 319.28 \\
Recessions & -47.73 & -3.61 & -5.81 \\
\hline EXCESS & & & \\
\hline Expansions & 6.95 & 24.49 & 4.54 \\
Recessions & -4.10 & 0.10 & -0.78 \\
\hline \hline
\end{tabular}

Notes: We use the NBER chronology as reference. 
TABLE 5

MS Estimation With Structural BREaks

\begin{tabular}{lccccc}
\hline \hline \multicolumn{7}{c}{$\mu_{1}$} & $\mu_{2}$ & $\sigma$ & $p$ & $q$ \\
\hline $1875.2-2014.2$ & 1.15 & -4.62 & 2.92 & 0.98 & 0.61 \\
& $(0.08)$ & $(0.35)$ & $(0.19)$ & $(0.00)$ & $(0.09)$ \\
\hline \multicolumn{7}{c}{ WITH 1} & BREAK & & \\
\hline $1875.2-1950.2$ & 1.52 & -4.30 & 4.66 \\
& $(0.14)$ & $(0.49)$ & $(0.45)$ & 0.95 & 0.65 \\
$1950.3-2014.2$ & 0.97 & -0.55 & 0.57 & $(0.001)$ & $(0.007)$ \\
& $(0.06)$ & $(0.24)$ & $(0.06)$ & & \\
\hline \multicolumn{7}{c}{ WITH 2 BREAKS } & & \\
\hline $1875.2-1946.1$ & 1.58 & -4.21 & 4.75 & & \\
& $(0.15)$ & $(0.51)$ & $(0.48)$ & & \\
$1946.2-1984.1$ & 1.29 & -0.27 & 0.90 & 0.95 & 0.71 \\
& $(0.14)$ & $(0.22)$ & $(0.14)$ & $(0.001)$ & $(0.007)$ \\
$1984.2-2014.2$ & 0.77 & -0.66 & 0.22 & & \\
& $(0.05)$ & $(0.25)$ & $(0.03)$ & & \\
\hline & WITH 3 BREAKS & & \\
\hline $1875.2-1917.2$ & 1.21 & -4.04 & 3.83 & & \\
& $(0.18)$ & $(1.86)$ & $(0.49)$ & \\
$1917.3-1946.1$ & 2.36 & -4.02 & 5.49 & 0.95 & 0.72 \\
& $(0.29)$ & $(0.63)$ & $(0.97)$ & $(0.001)$ & $(0.007)$ \\
$1946.2-1984.1$ & 1.30 & -0.26 & 0.89 & & \\
& $(0.14)$ & $(0.21)$ & $(0.14)$ & & \\
$1984.2-.2014 .2$ & 0.77 & -0.65 & 0.22 & & \\
& $(0.05)$ & $(0.25)$ & $(0.03)$ & & \\
\hline \hline
\end{tabular}

Notes: We introduce structural breaks in variance in a twostates Markov-Switching model. 
TABLE 6

MS ESTIMATION WITH VARIANCE REGIMES

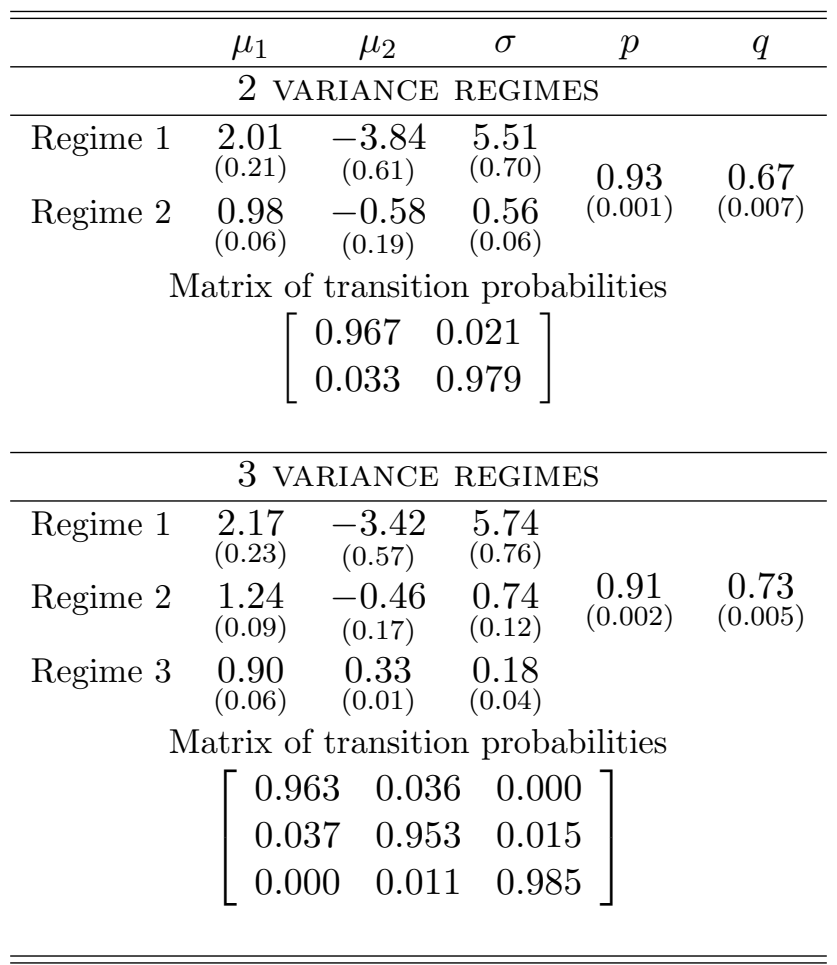

Notes: We have estimated a two-states Markov-Switching model with 2 and 3 variance regimes. 
TABLE 7

MS Estimation with Finite mixtures

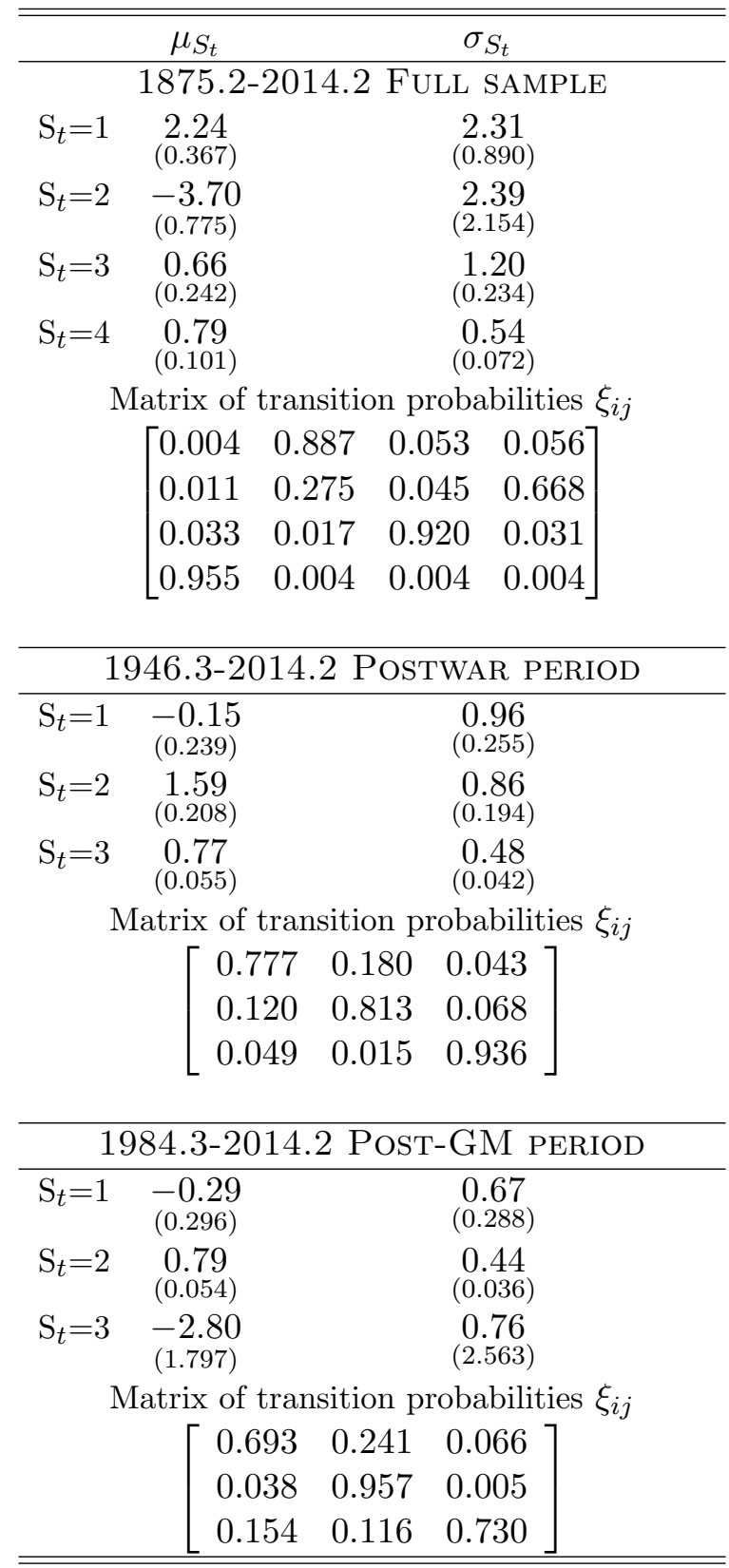

Notes: Standard errors in parentheses. 


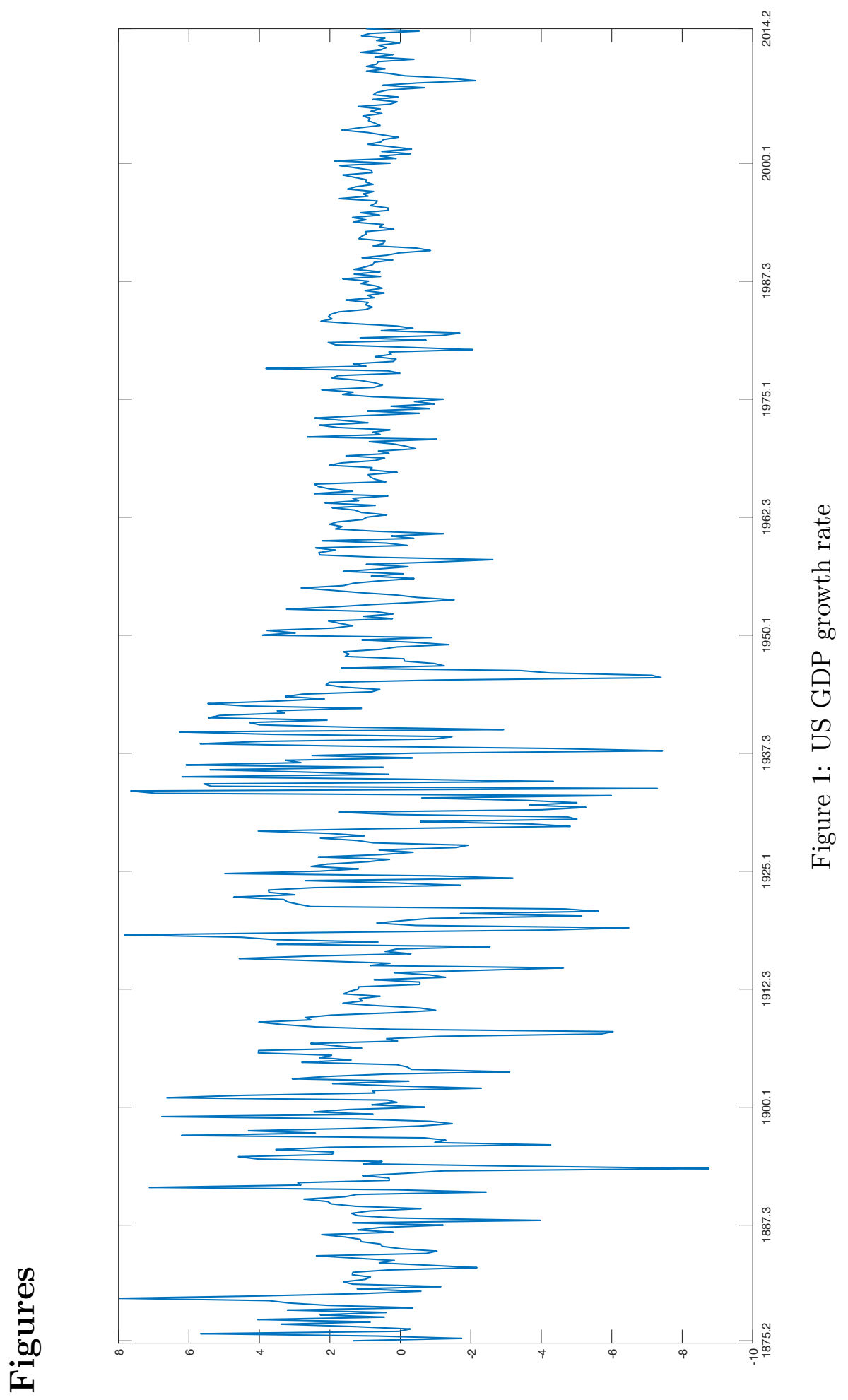




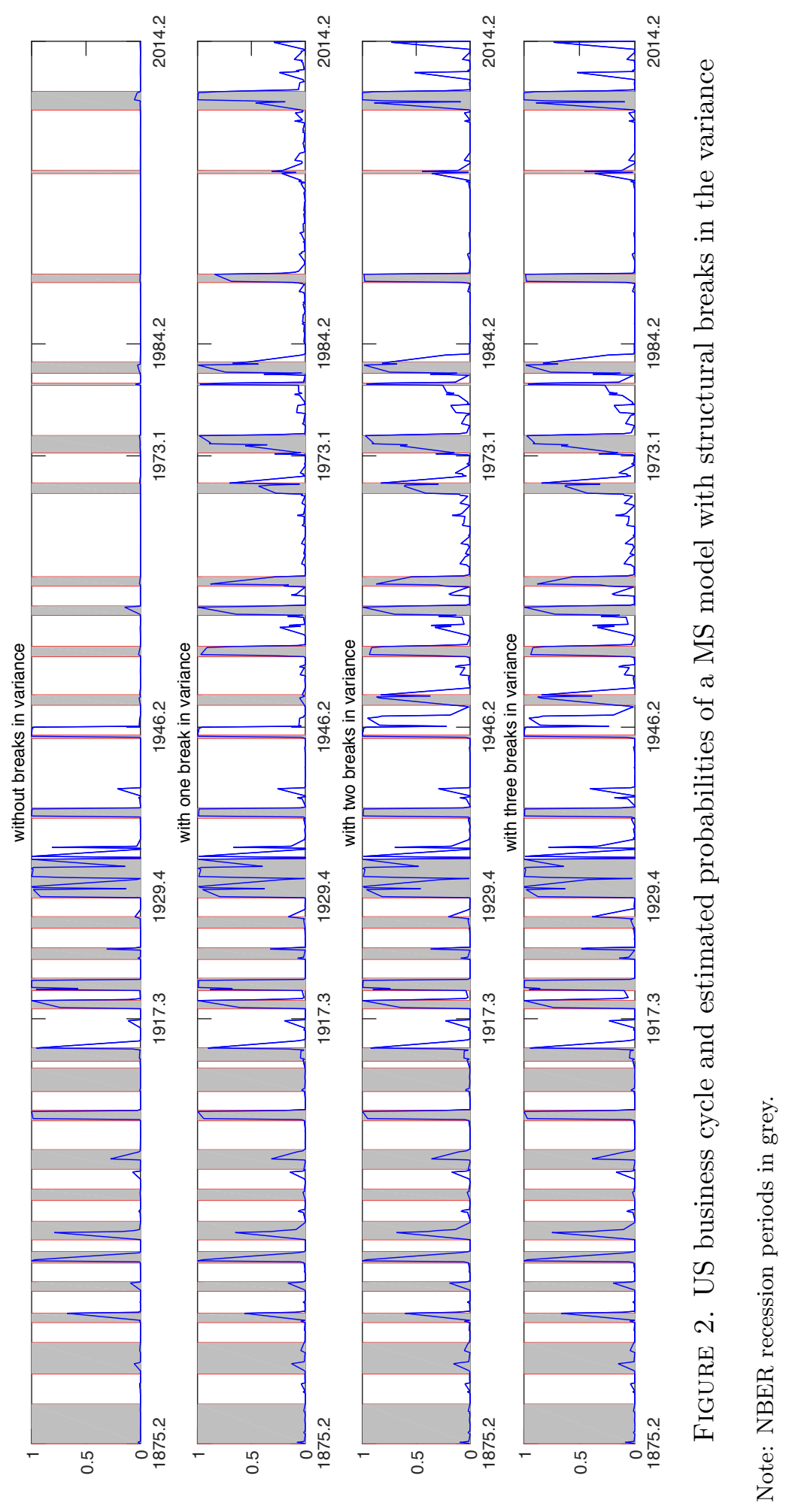




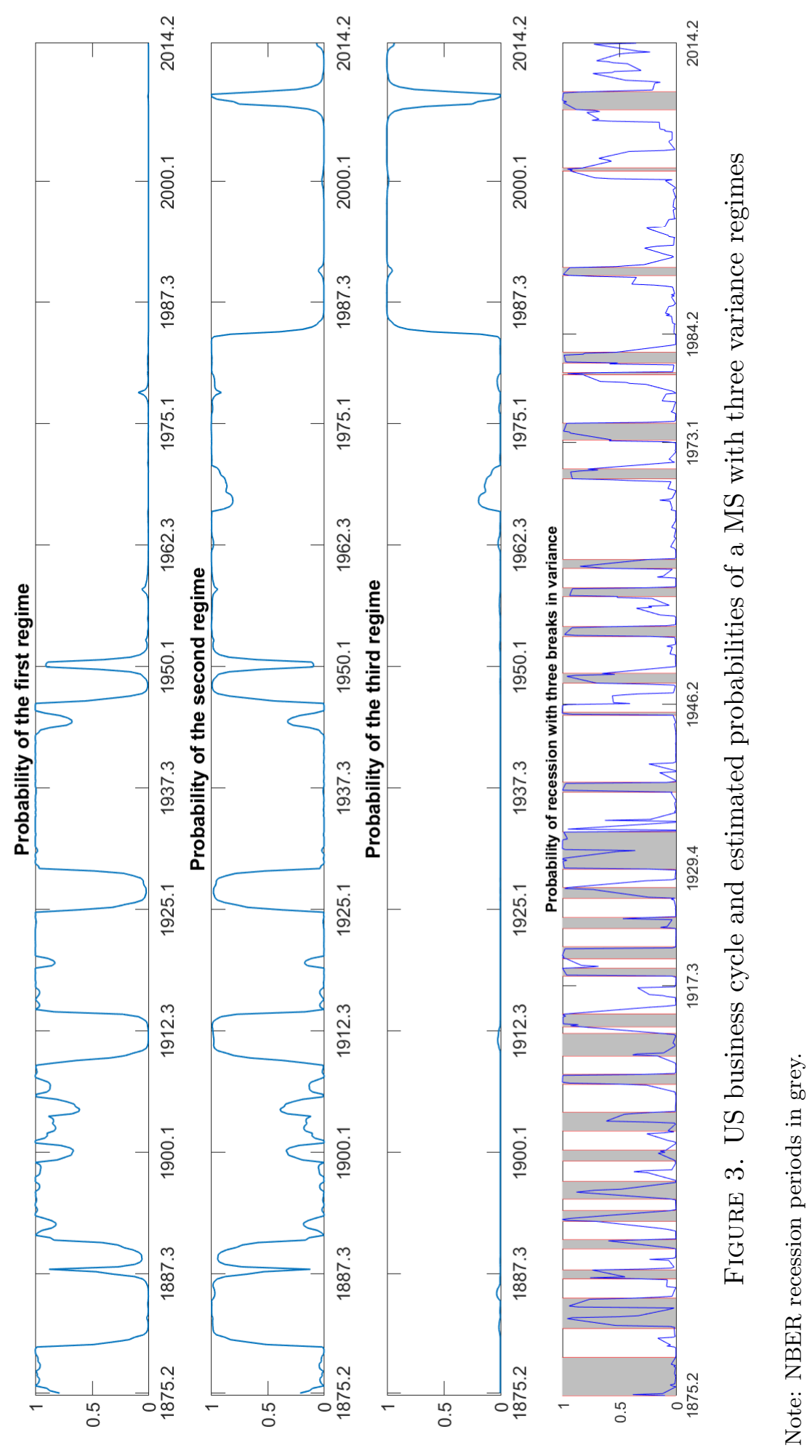




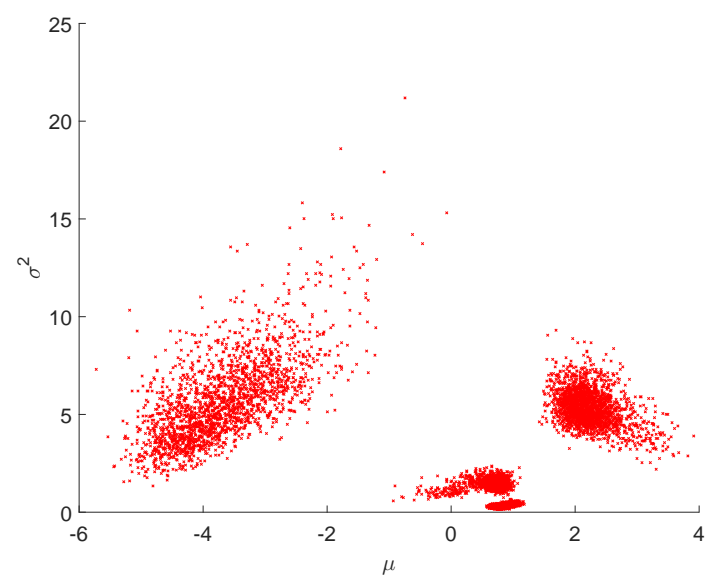

(a) Draw point process representation $\mathrm{K}=4$
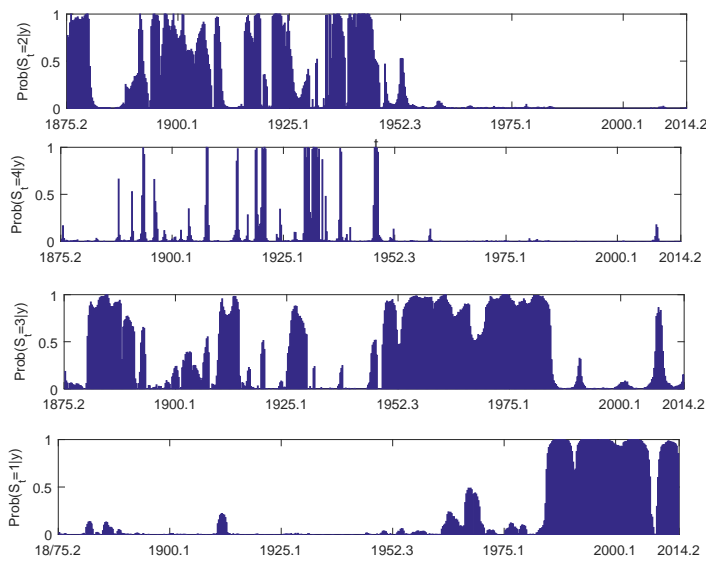

(b) Smoothed states probabilities

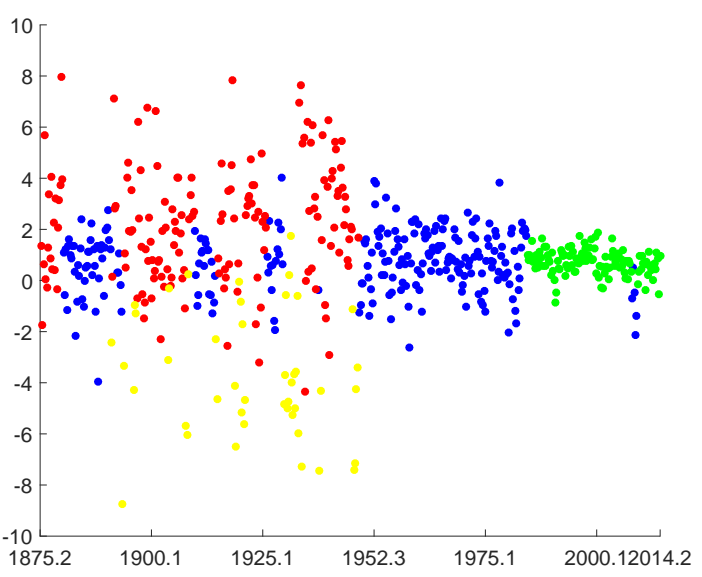

(c) Time series classification

FIGURE 4. Results of estimating a Markov mixture: 1875.2-2014.2

Notes: Panel (a) displays the scatterplot of MCMC draws for $\mu$ and $\sigma$. Panel (b) represents the probability of being in each state. Panel (c) shows GDP growth based on belonging to each state. The first state appears in red, the second in yellow, the third in blue and the fourth one in green. 


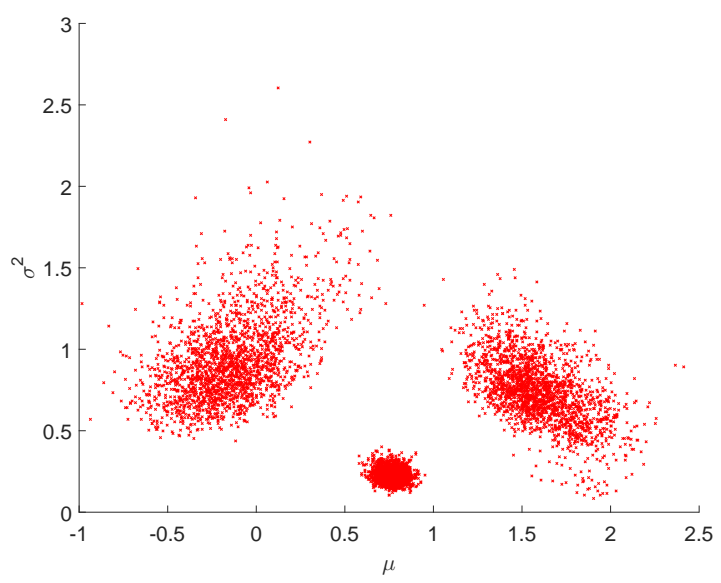

(a) Draw point process representation $\mathrm{K}=3$
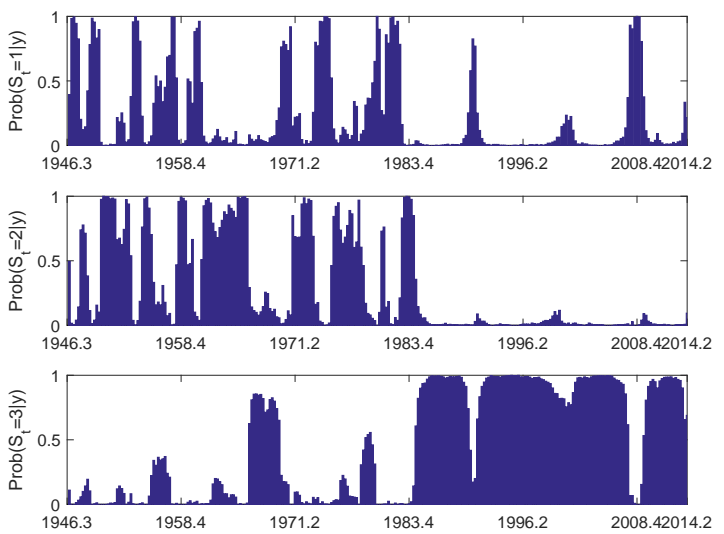

(b) Smoothed states probabilities

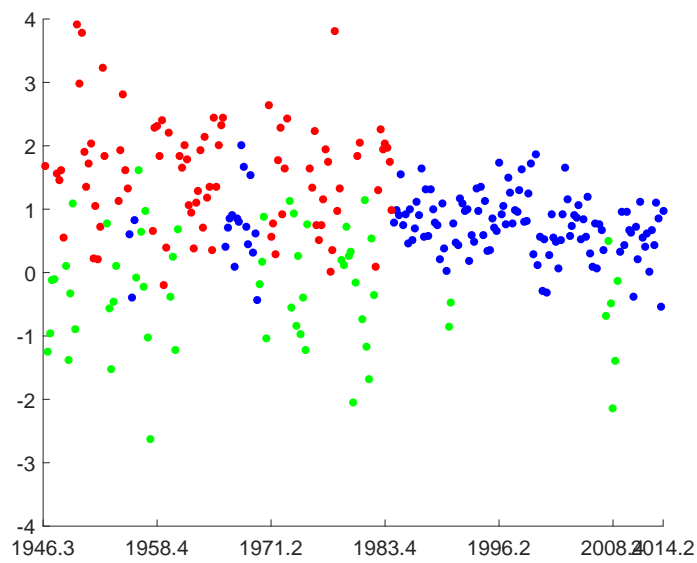

(c) Time series classification

FIGURE 5. Results of estimating a Markov mixture: 1946.3-2014.2

Notes: Panel (a) displays the scatterplot of MCMC draws for $\mu$ and $\sigma$. Panel (b) represents the probability of being in each state. Panel (c) shows GDP growth based on belonging to each state. The first state appears in green, the second in red and third one in blue. 


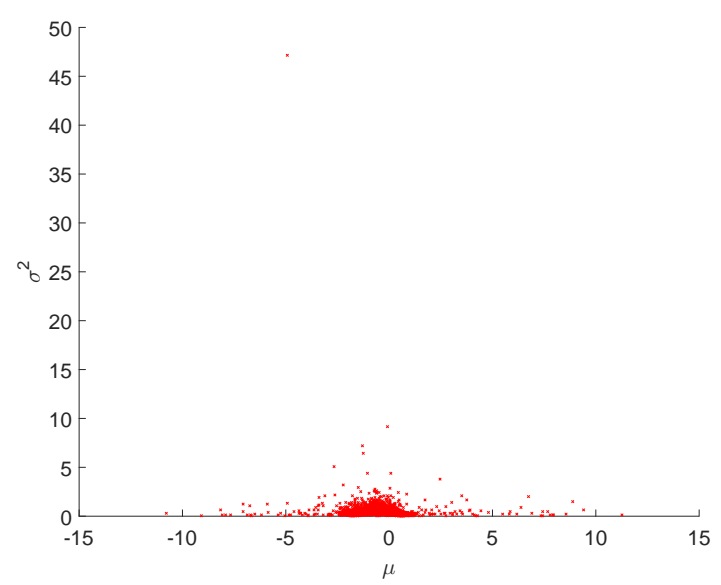

(a) Draw point process representation $\mathrm{K}=3$
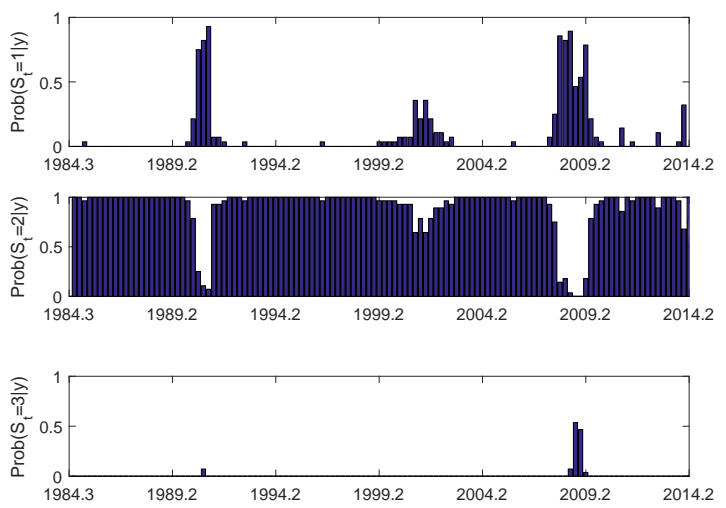

(b) Smoothed states probabilities

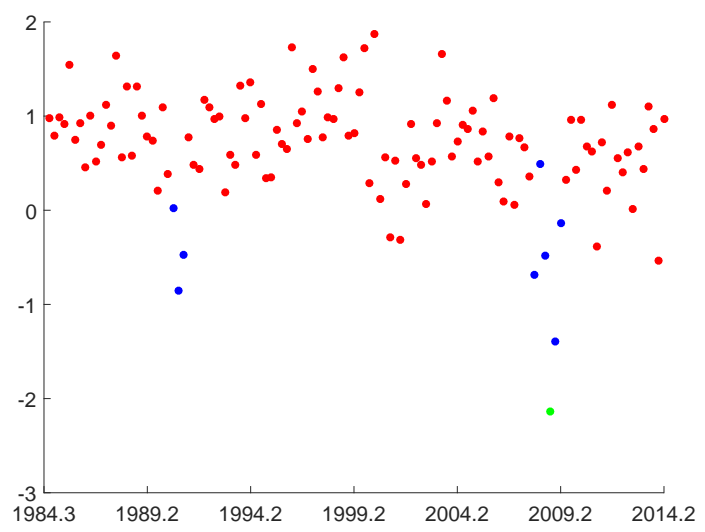

(c) Time series classification

Figure 6. Results of estimating a Markov mixture: 1984.3-2014.2

Notes: Panel (a) displays the scatterplot of MCMC draws for $\mu$ and $\sigma$. Panel (b) represents the probability of being in each state. Panel (c) shows shows GDP growth based on belonging to each state. The first state appears in blue, the second in red and the third one in green. 


\section{Appendix A. Monte Carlo exercises}

To examine power and size of our finding on the contribution that business cycle phases make to structural breaks in volatility, we have designed two Monte Carlo exercises. The first one, exercise A, examines features associated to the post-World War II volatility reduction, while the second one, exercise B, explores the characteristics of the Great Moderation volatility decline.

\section{Exercise A: WWII structural break in volatility}

We highlight in the main text that the origin of the WWII volatility break is a change in the frequency and size of expansions and recessions. The procedure followed in the paper to show it is to change the expansions and recessions of period 2 (1946.3-1984.2) with those of period 1 (1875.2-1946.2). When we change recessions, the structural break is found in almost half of all cases and; when we change expansions, the structural break is found in $31 \%$. Then, we conclude it is a mixture of expansion and recession features what is behind the WWII volatility break.

In this Monte Carlo exercise, we focus on the effects of changing frequency and size of the business cycle phases, which can be introduced by means of different parameters of a Markov Switching (MS) specification. ${ }^{1}$. Specifically, we change the probabilities of staying in expansion and in recession ( $p$ and $q$, respectively) to analyze frequency, and the mean growth rates in expansion and in recession ( $\mu_{1}$ and $\mu_{2}$, respectively), to size.

We consider 4 different cases. Each case is composed of two subsamples with 150 observations each. The first subsample corresponds to replications generated with a MS model with the parameters calculated to match the data of period 1 ( $p=0.89, q=0.85, \mu_{1}=2.02$ and $\left.\mu_{2}=-0.81\right)$. The second subsample corresponds either with the same parameters of period 1 (case 1) or with some parameters of a MS model estimated for period $2\left(p=0.92, q=0.73, \mu_{1}=1.20\right.$ and $\left.\mu_{2}=-0.51\right)$. In particular, in case 2, we check the effect of changes in frequency ( $p$ and $q$ ); in case 3 , the effect of changes in size $\left(\mu_{1}\right.$ and $\left.\mu_{2}\right)$ and; in case 4 , the effect of both. See details in Table A1. The total length in each case is 300 observations.

\footnotetext{
${ }^{1}$ The suitability of this technique to match the data of each period is shown in Section 4.
} 
Table A1: Cases Exercise A

\begin{tabular}{cccccccccc}
\hline \hline & \multicolumn{3}{c}{ First subsample } & \multicolumn{4}{c}{ Second subsample } \\
\hline & $\mathrm{p}$ & $\mathrm{q}$ & $\boldsymbol{\mu}_{1}$ & $\mu_{2}$ & $\mathrm{p}$ & $\mathrm{q}$ & $\mu_{1}$ & $\mu_{2}$ \\
\hline Case 1 & 0.89 & 0.85 & 2.02 & -0.81 & 0.89 & 0.85 & 2.02 & -0.81 \\
Case 2 & 0.89 & 0.85 & 2.02 & -0.81 & 0.93 & 0.73 & 2.02 & -0.81 \\
Case 3 & 0.89 & 0.85 & 2.02 & -0.81 & 0.89 & 0.85 & 1.20 & -0.51 \\
Case 4 & 0.89 & 0.85 & 2.02 & -0.81 & 0.93 & 0.73 & 1.20 & -0.51 \\
\hline \hline
\end{tabular}

We generate 10,000 replications of these four processes and test the number of rejections of the null hypothesis $H_{0}$ that there is no structural break in volatility, by using the modified test of Inclán and Tiao (1994). In case 1, we are measuring the size and in the rest of cases, the power.

\section{Exercise B: Great Moderation structural break in volatility}

In the main text of the paper we find that the nature of the Great Moderation structural break in volatility is related to changes in the characteristics of expansionary phases. Specifically, we identify that if we change the recessions of period 3 (1984.3-2014.2) with the recessions of period 2, we obtain the GM structural break in $100 \%$ of the cases. However, if we change the expansions of the period 3 with those of period 2, in no case does the structural break of the GM hold.

Bearing this in mind, we design a Monte Carlo exercise on expansions taking two issues into account. On the one hand, duration and amplitude, which can be measured through $p$ and $\mu_{1}$ parameters of a MS specification and, ${ }^{2}$ on the other hand, shape, which is introduced by means of a concavity function.

We consider 4 cases. Each case is composed of two subsamples with 150 observations each. The first subsample corresponds to replications generated with a MS model with the parameters estimated for period $2\left(p=0.92, q=0.73, \mu_{1}=1.20\right.$ and $\left.\mu_{2}=-0.51\right)$. Furthermore, we find in the paper that period 2 is characterized by a concave shape of expansions. Hence, we also introduce

\footnotetext{
${ }^{2}$ Notice that the higher $p$, the longer the expansion and the lower $\mu_{1}$, the flatter the expansion. With higher $p$ and lower $\mu_{1}$, the volatility would be lower.
} 
concavity. We do it by means of a concavity function of the form $Y=\left(a-b(x-c)^{2}\right)$, defined on the $[0,1]$ interval. The parameter $b$ determines the degree of concavity of this function. We have selected $b=2$ to get a volatility similar to that of period 2 . The rest of parameters are obtained as follows: $c=(1+b) /(2 * b)$ and $a=b * c^{2}$, to impose than the range and the domain of the function lie between 0 and 1. We apply this function to the GDP growth rate during expansions. We normalize the function depending on the duration and amplitude of each expansion. ${ }^{3}$

The second subsample differs depending on the case. Specifically, in case 1, the second subsample is the same than the first. In case 2 , we introduce $p$ and $\mu_{1}$ of a MS model with the parameters for period 3 ( $p=0.97, q=0.73, \mu_{1}=0.77$ and $\mu_{2}=-0.47$ ). In case 3 , we introduce the parameters of the MS model generated for period 2, but making the shape to be linear. In case 4, we introduce the $p$ and $\mu_{1}$ of the MS model with the parameters for period 3 and also modify the shape to be linear. See Table A2 for details. Notice that, as this exercise focuses on expansions, we keep fixed the parameters associated with recessions in all the cases. However, they are very similar between period 2 and 3 . The total length in each case is 300 observations.

Table A2: Cases Exercise B

\begin{tabular}{ccccccccccc}
\hline \hline \multicolumn{4}{c}{ First subsample } & \multicolumn{5}{c}{ Second subsample } \\
\hline & $\mathrm{p}$ & $\mathrm{q}$ & $\mu_{1}$ & $\mu_{2}$ & Shape & $\mathrm{p}$ & $\mathrm{q}$ & $\mu_{1}$ & $\mu_{2}$ & Shape \\
\hline Case 1 & 0.93 & 0.73 & 1.20 & -0.51 & Concave & 0.93 & 0.73 & 1.20 & -0.51 & Concave \\
Case 2 & 0.93 & 0.73 & 1.20 & -0.51 & Concave & 0.96 & 0.73 & 0.77 & -0.51 & Concave \\
Case 3 & 0.93 & 0.73 & 1.20 & -0.51 & Concave & 0.93 & 0.73 & 1.20 & -0.51 & Linear \\
Case 4 & 0.93 & 0.73 & 1.20 & -0.51 & Concave & 0.96 & 0.73 & 0.77 & -0.51 & Linear \\
\hline \hline
\end{tabular}

As in Exercise A, we generate 10,000 replications of these four processes and test the number of rejections of the null hypothesis $H_{0}$ that there is no structural break in volatility, by using the modified test of Inclán and Tiao (1994). In case 1, we are measuring the size and in the rest of cases, the power.

\footnotetext{
${ }^{3}$ We adjust the domain of the function to the duration of each expansion and the range, to the amplitude of each expansion.
} 


\section{Results}

The results displayed in Table A3 show that, for Exercise A, the test has good size properties with a value of $5.50 \%$ (case 1). The exercise also shows that the test has good power properties. When we change the characteristics of expansions and recessions of period 1 for those of period 2, we find the WWII structural break in $95.40 \%$ of replications (case 4). We also find greater sensitivity to size than to frequency (case 3 vs. case 2). We observe that the different generated processes hardly reduce the frequency of recessions, while there is an important decline in volatility from period 1 to period 2 .

Regarding Exercise B, we again find that the size of the test is suitable in case $1(0.60 \%){ }^{4}$ The test has also good power properties. When we change duration, amplitude and shape of expansions, we reject the null hypothesis in $99.8 \%$ of replications (case 4). We also observe greater sensitivity to the shape than to duration and amplitude (case 3 vs. case 2). Finally, we find that there is an important decline in volatility from period 2 to period 3, particularly high in the cases 3 and 4 .

\footnotetext{
${ }^{4}$ Results on size show that, when including concavity, this is a conservative test.
} 
Table A3. Results of Monte Carlo exercises

\begin{tabular}{|c|c|c|c|c|}
\hline \multicolumn{5}{|c|}{ Exercise A } \\
\hline Cases & 1 & 2 & 3 & 4 \\
\hline \%rejections $H_{0}$ & 0.0550 & 0.1310 & 0.9340 & 0.9540 \\
\hline Frequency of recessions & 0.4138 & 0.3147 & 0.4138 & 0.3147 \\
\hline Volatility(st.dev.) & & & & \\
\hline Full period & 1.6996 & 1.6318 & 1.5129 & 1.4744 \\
\hline Period 1 & 1.6864 & 1.6864 & 1.6864 & 1.6864 \\
\hline Period 2 & 1.6891 & 1.5143 & 1.2947 & 1.2136 \\
\hline \multicolumn{5}{|c|}{ Exercise B } \\
\hline Cases & 1 & 2 & 3 & 4 \\
\hline \%rejections $H_{0}$ & 0.0060 & 0.8130 & 0.9810 & 0.9980 \\
\hline Frequency of recessions & 0.2191 & 0.2014 & 0.2191 & 0.2014 \\
\hline Volatility(st.dev.) & & & & \\
\hline Full period & 1.2923 & 1.1034 & 1.0441 & 0.9742 \\
\hline Period 2 & 1.3066 & 1.2967 & 1.2967 & 1.2967 \\
\hline Period 3 & 1.2842 & 0.8526 & 0.6948 & 0.4427 \\
\hline
\end{tabular}

